\title{
Expression of MMP-9 in different degrees of chronic hepatitis $B$ and its correlation with inflammation
}

\author{
YUJUAN LI*, HONGTAO LIU* and LIXIU XU* \\ Laboratory Department, Dongying People's Hospital, Dongying, Shandong 257091, P.R. China
}

Received April 26, 2018; Accepted August 8, 2018

DOI: $10.3892 / e t m .2018 .6673$

\begin{abstract}
Expression of matrix metalloproteinase-9 (MMP-9) in different degrees of chronic hepatitis $\mathrm{B}$ (CHB) and the correlation of MMP-9 with inflammation was investigated. A total of 96 CHB patients (observation group) admitted and treated in Dongying People's Hospital from December 2016 to November 2017 were selected, and they were compared with 60 healthy individuals (control group) selected in the physical examination center during the same time period. Enzyme-linked immunosorbent assay (ELISA) was used to detect the expression of MMP-9, tumor necrosis factor- $\alpha$ (TNF- $\alpha$ ) and interleukin-6 (IL-6), MMP-9 expression in different inflammation grades and fibrosis stages, and the relationship between MMP-9 and inflammation was analyzed. The levels of MMP-9, TNF- $\alpha$ and IL-6 in serum in the observation group were obviously higher than those in the control group $(\mathrm{P}<0.05)$. The rank sum test indicated that there were statistically significant differences in the expression levels of MMP-9 among the inflammation grades G0, G1, G2, G3 and G4 $(\mathrm{P}<0.05)$. The expression levels of MMP-9 in fibrosis stages S0, S1, S2, S3 and S4 were detected via the rank sum test, and it suggested that the differences among the 5 stages were statistically significant $(\mathrm{P}<0.05)$. Pearson's correlation analysis showed that the MMP-9 expression level was positively correlated with TNF- $\alpha$ and IL-6 $(\mathrm{P}<0.05)$. In conclusion, the MMP-9 level is elevated remarkably in patients with varying degrees of $\mathrm{CHB}$, it may play an important role in the pathological progress of liver, and it has a close correlation with inflammation, which can provide a theoretical basis for clinical treatment.
\end{abstract}

Correspondence to: Dr Lixiu Xu, Laboratory Department, Dongying People's Hospital, 317 South Road, Dongcheng, Dongying, Shandong 257091, P.R. China

E-mail: xulixiu612@163.com

${ }^{*}$ Contributed equally

Key words: chronic hepatitis B, MMP-9, TNF- $\alpha$, IL-6

\section{Introduction}

Chronic hepatitis B (CHB) is one of the most common of chronic viral infectious diseases, which is mainly transmitted by contacting the blood and body fluids of the infected people (1). More than 350 million people have been infected with CHB all over the world so far. CHB is the leading cause of liver cirrhosis and hepatocellular carcinoma as well as death of nearly 600,000 people every year, becoming one of the worldwide primary health problems (2). Currently, the control rate of CHB is $<0.5 \%$ in some regions, and the disease mainly occurs among young people. In some regions of Asia and Africa, mother-to-child transmission is the most common route of transmission of $\mathrm{CHB}$, with a prevalence rate exceeding $10 \%$ (3). CHB is characterized by recurrent attacks and prolonged courses, and it can easily induce liver fibrosis, thus leading to liver cirrhosis (4). The pathological characteristic of liver fibrosis is excessive deposition of extracellular matrix (ECM) in perisinusoidal space. Hepatitis B virus (HBV) is the initiating agent of aggravated severity of $\mathrm{CHB}$, and apoptosis of liver cells induced by varying degrees of inflammation plays an important role in the outcome of CHB (5). Matrix metalloproteinase-9 (MMP-9) is a type of polypeptidase that can hydrolyze ECM (6), but the relationship of its level with the severity of CHB still remains unclear at present. In this study, the correlation of MMP-9 with inflammation was investigated by means of analyzing the MMP-9 expression in different inflammation grades and fibrosis stages of $\mathrm{CHB}$, hoping to provide a basis for controlling and reversing exacerbation of CHB degree.

\section{Patients and methods}

Clinical data. A total of 96 CHB patients admitted and treated in Dongying People's Hospital (Dongying, China) from December 2016 to November 2017 were selected as the observation group. The inclusion criteria were as follows: i) patients who met the diagnostic criteria of CHB (7), ii) patients who did not receive antiviral therapy before admission to hospital, and iii) patients who signed informed consent. The exclusion criteria were as follows: i) patients with hepatitis A, C, D and E, and ii) patients with malignant tumor as well as pregnant and breast-feeding women. In addition, a total of 60 unrelated healthy individuals in the physical examination center during the same time period were selected as the control group. There 
Table I. Comparison of general data of the two groups of patients.

\begin{tabular}{|c|c|c|c|c|}
\hline Items & Control group $(\mathrm{n}=60)$ & Observation group $(n=60)$ & $t / \chi^{2}$ & P-value \\
\hline Sex (male/female) & $35 / 25$ & $57 / 39$ & 0.047 & 0.828 \\
\hline Age (years) & $40-80$ & $40-75$ & & \\
\hline Average age (years) & $52.36 \pm 8.46$ & $52.78 \pm 7.58$ & 0.322 & 0.748 \\
\hline BMI $\left(\mathrm{kg} / \mathrm{m}^{2}\right)$ & $23.28 \pm 1.15$ & $23.56 \pm 1.17$ & 1.464 & 0.145 \\
\hline \multicolumn{5}{|l|}{ Education level (n, \%) } \\
\hline Junior high school and below & $16(26.67)$ & $25(26.04)$ & 0.126 & 0.939 \\
\hline Senior high school and special secondary school & $25(41.67)$ & $38(39.58)$ & & \\
\hline College and above & $19(31.63)$ & $33(34.38)$ & & \\
\hline
\end{tabular}

BMI, body mass index.

Table II. Criteria of determining degrees of liver tissue inflammation and fibrosis.

\begin{tabular}{|c|c|c|c|}
\hline Liver tissue inflammation & Grade & Fibrosis degree & Stage \\
\hline No inflammation & 0 & No fibrosis & 0 \\
\hline $\begin{array}{l}\text { Intralobar degeneration and a few spotted } \\
\text { and focal necrotic foci, } \\
\text { and inflammation in portal area }\end{array}$ & 1 & $\begin{array}{l}\text { Expanded fibrosis in portal area, } \\
\text { localized fibrosis } \\
\text { in lobule and perisinusoidal space }\end{array}$ & 1 \\
\hline $\begin{array}{l}\text { Intralobar degeneration and spotted and focal necrosis } \\
\text { or eosinophilic bodies, } \\
\text { and mild piecemeal necrosis in portal area }\end{array}$ & 2 & $\begin{array}{l}\text { Fibrosis around portal area, } \\
\text { formation of fibrous septa, } \\
\text { and reservation of lobular architecture }\end{array}$ & 2 \\
\hline $\begin{array}{l}\text { Intralobar degeneration and confluent necrosis or } \\
\text { bridging necrosis, and moderate } \\
\text { piecemeal necrosis in portal area }\end{array}$ & 3 & $\begin{array}{l}\text { Formation of fibrous septa associated with } \\
\text { disorganized lobular architecture, } \\
\text { without liver cirrhosis }\end{array}$ & 3 \\
\hline $\begin{array}{l}\text { Extensive bridging necrosis affecting several lobules, } \\
\text { and severe piecemeal necrosis in portal area }\end{array}$ & 4 & Liver cirrhosis at early stage & 4 \\
\hline
\end{tabular}

were no statistically significant differences in the general data of the two groups of patients $(\mathrm{P}>0.05)$, and the data were comparable (Table I).

This study was approved by the Ethics Committee of Dongying People's Hospital. Signed informed consents were obtained from the patients or guardians.

Methods. A total of $5 \mathrm{ml}$ venous blood was collected from every research object (fasted for $8 \mathrm{~h}$ from 7:00 a.m.), and was centrifuged (Eppendorf Shanghai International Trade Co. Ltd., Shanghai, China) at $950 \mathrm{x}$ g for $10 \mathrm{~min}$ and then stored in a refrigerator at $-20^{\circ} \mathrm{C}$. Enzyme-linked immunosorbent assay (ELISA) was used to detect the levels of MMP-9, tumor necrosis factor- $\alpha$ (TNF- $\alpha$ ) and interleukin-6 (IL-6) in the serum, relevant kits were provided by Beijing Donggeboye Biological Technology Co., Ltd. (Beijing, China) and the operations were performed in strict accordance with the kit instructions. The sample (diluted at 1:2) was added into the wells of microplate reader (Shenzhen SinoThinker Technology Co., Ltd., Shenzhen, China), with $100 \mu 1$ enzyme-labeled solution in each well. Then the sample was incubated at $37^{\circ} \mathrm{C}$ for $90 \mathrm{~min}$, and the microplate reader was washed 3 times. After that, $50 \mu \mathrm{l}$ of color developing reagent solution Aand B was added and mixed respectively, followed by incubation in the dark at room temperature $\left(20^{\circ} \mathrm{C}\right)$ for 15 min. Finally, the optical density (OD) was measured at a wavelength of $450 \mathrm{~nm}$ with a microplate reader within 15 min, and the levels of MMP-9, TNF- $\alpha$ and IL-6 were calculated.

Evaluation criteria. Criteria of determining different degrees of CHB: the liver tissue inflammation was divided into 5 grades and the fibrosis was divided into 5 stages (8) (Table II). A total of $5 \mathrm{ml}$ venous blood was collected from every research object in the two groups, and the serum MMP-9, TNF- $\alpha$ and IL-6 levels were measured using ELISA.

Statistical analysis. Statistical Product and Service Solutions (SPSS) 19.0 (IBM Corp., Armonk, NY, USA) software was applied to process the data. The measurement data are presented as mean \pm standard deviation, and t-test was adopted. The enumeration data were expressed by ratio, and $\chi^{2}$ test was performed. The expression of MMP-9 in different degrees of lesion was examined via rank sum test, and the P-value was calibrated using Bonferroni method. Pearson's correlation coefficients were utilized to analyze the correlations. $\mathrm{P}<0.05$ was considered to indicate a statistically significant difference. 
Table III. Comparison of MMP-9, TNF- $\alpha$ and IL-6 levels in the two groups of patients.

\begin{tabular}{lcccc}
\hline Groups & $\mathrm{n}$ & MMP-9 $(\mathrm{ng} / \mathrm{ml})$ & $\mathrm{TNF}-\alpha(\mathrm{ng} / \mathrm{l})$ & $\mathrm{IL}-6(\mathrm{ng} / \mathrm{ml})$ \\
\hline Observation & 96 & $256.95 \pm 15.13$ & $79.97 \pm 6.47$ & $56.76 \pm 6.38$ \\
Control & 60 & $90.69 \pm 9.06$ & $26.73 \pm 6.86$ & $4.43 \pm 1.27$ \\
t value & & 76.884 & 48.853 & 77.932 \\
P-value & & $<0.001$ & $<0.001$ & $<0.001$ \\
\hline
\end{tabular}

MMP-9, matrix metalloproteinase- 9 ; TNF- $\alpha$, tumor necrosis factor- $\alpha$; IL-6, interleukin-6.

Table IV. Relations between MMP-9 level and different inflammation grades.

\begin{tabular}{lrcr}
\hline Inflammation grade & $\mathrm{n}$ & MMP-9 $(\mathrm{ng} / \mathrm{ml})$ & P-value \\
\hline G0 & 16 & $98.95 \pm 9.13$ & $<0.001$ \\
G1 & 30 & $143.69 \pm 9.56$ & \\
G2 & 26 & $218.95 \pm 13.13$ & \\
G3 & 18 & $283.69 \pm 16.06$ & \\
G4 & 6 & $318.69 \pm 20.06$ & \\
\hline
\end{tabular}

MMP-9, matrix metalloproteinase-9.

Table V. Association of MMP-9 level with different stages of fibrosis.

\begin{tabular}{lccc}
\hline Fibrosis stage & $\mathrm{n}$ & MMP-9 $(\mathrm{ng} / \mathrm{ml})$ & P-value \\
\hline S0 & 19 & $97.49 \pm 9.04$ & $<0.001$ \\
S1 & 28 & $153.58 \pm 10.45$ & \\
S2 & 25 & $218.37 \pm 15.42$ & \\
S3 & 17 & $298.65 \pm 17.46$ & \\
S4 & 7 & $343.84 \pm 21.12$ & \\
\hline
\end{tabular}

MMP-9, matrix metalloproteinase-9.

\section{Results}

MMP-9, TNF- $\alpha$ and IL-6 expression in the two groups of research objects. The levels of serum MMP-9, TNF- $\alpha$ and IL-6 in the observation group were obviously higher than those in the control group $(\mathrm{P}<0.05)$ (Table III).

MMP-9 expression in different inflammation grades. The MMP-9 expression level was increased with the aggravated inflammation activity, and the differences were statistically significant among the 5 groups $(\mathrm{P}<0.05)$ (Table IV). It is indicated in the rank sum test that there is statistical significance in the MMP-9 level among different inflammation grades $(\mathrm{P}<0.05)$. Pairwise comparisons using the Bonferroni method suggest that the differences in MMP-9 level among the groups are statistically significant $(\mathrm{P}<0.05)$.

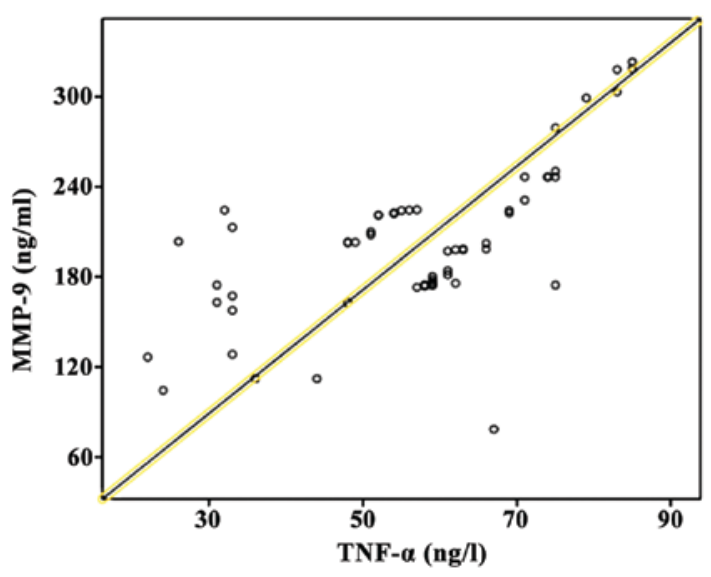

Figure 1. Correlation of MMP-9 expression level with TNF- $\alpha$. Pearson correlation coefficient analysis showed that the MMP-9 expression level was positively correlated with TNF- $\alpha(\mathrm{P}<0.05)$. MMP-9, MMP-9, matrix metalloproteinase-9; TNF- $\alpha$, tumor necrosis factor- $\alpha$.

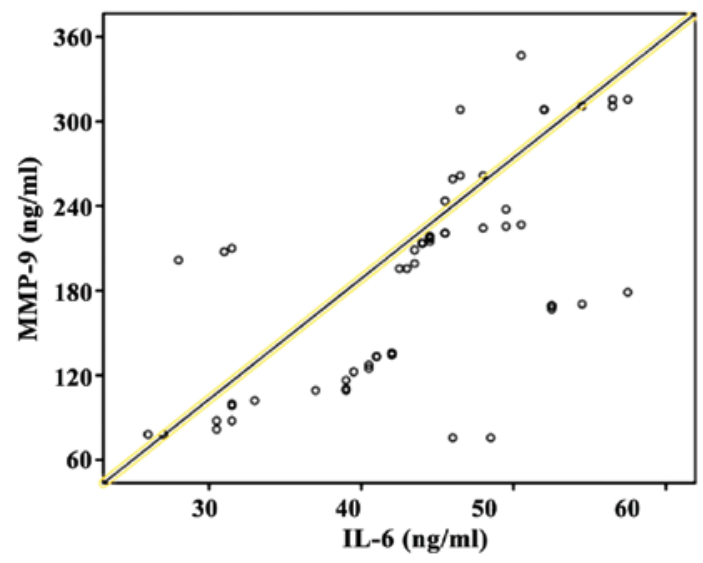

Figure 2. Correlation of MMP-9 expression level with IL-6. Pearson correlation coefficient analysis showed that the MMP-9 expression level was positively correlated with IL-6 ( $<<0.05)$. MMP-9, MMP-9, matrix metalloproteinase-9; IL-6, interleukin-6.

MMP-9 expression in different fibrosis stages. The MMP-9 expression level was elevated with the increased fibrosis stage, and the differences among the 5 groups were statistically significant $(\mathrm{P}<0.05)$ (Table $\mathrm{V})$. It is indicated in the rank sum test that there is statistical significance in the MMP-9 level in different fibrosis stages $(\mathrm{P}<0.05)$. Pairwise comparison using the Bonferroni method suggest that the differences in MMP-9 level among the groups are statistically significant $(\mathrm{P}<0.05)$.

Analysis of correlation of MMP-9 expression level with inflammation. Pearson's correlation coefficient analysis showed that the MMP-9 expression level was positively correlated with TNF- $\alpha$ and IL-6 (P<0.05) (Figs. 1 and 2).

\section{Discussion}

The liver, a vital organ in the body that is responsible for various kinds of biotransformation and storage, plays an important role in the synthesis of coagulation factors, storage and metabolism of fats and proteins as well as secretion and detoxication of bile (9). Multiple types of hepatitis occur easily after the liver is 
infected by pathogens, dominated by $\mathrm{CHB}$ which has the highest incidence rate among the infectious diseases of the digestive system (10). According to the report of the World Health Organization (WHO), there are approximately 350 million CHB patients around the globe, including nearly 28 million patients in China, where the incidence rate is $\sim 2 \%$ (11). CHB can easily develop into liver cirrhosis and result in liver cancer if it is not treated in time (12). The pathogenesis of CHB is very complex, which has not been elaborated completely yet. It may be related to impacts of multiple factors, such as hepatitis virus, apoptosis-related gene, autoimmunity and cell molecules (13). The pathological manifestations of $\mathrm{CHB}$ include massive apoptosis of hepatocytes, severe liver dysfunction and abnormal biochemical markers of liver function. Currently, there is no ideal therapeutic method for CHB in clinic, and the major treatment strategies are stimulation of the patient's immune responses and repression of HBV replication (14).

MMP-9 is a kind of gelatinase substance secreted by many cells, such as neutrophils, macrophages and capillary endothelial cells, and it is a member of matrix metalloproteinases (MMPs) (15). MMP-9 can participate in the metabolism of collagen type IV in basement membrane, degrade ECM and be widely involved in multiple types of tumor metastasis by degrading ECM. In addition, it can induce basic fibroblast growth factor and vascular endothelial growth factor and promote tumor neovascularization (16). A study has revealed that MMP-9 is closely related to CHB (17). TNF- $\alpha$ is the first inflammatory mediator produced in the body, which plays a core role in the occurrence and development of $\mathrm{CHB}$ and has crucial functions in the induction of inflammatory responses, anti-infection and host defense (18). IL-6 is a kind of lymphocyte factor of acute phase reaction with diversified effects, which accelerates the proliferation of myofibroblasts and leads to liver fibrosis in CHB patients (19). The results of this study showed that the levels of serum MMP-9, TNF- $\alpha$ and IL- 6 in CHB patients were significantly higher than those in normal population $(\mathrm{P}<0.05)$. It is because the main pathological change of $\mathrm{CHB}$ is inflammation in the liver. The peripheral blood mononuclear cell (PBMC) may inhibit and attenuate the body's antiviral immune responses through exogenous and endogenous apoptotic pathways, thus causing constant replication of HBV. Moreover, it may activate inflammatory responses, thus increasing the levels of TNF- $\alpha$ and IL-6 (20). The activities of MMPs in the body are controlled strictly under normal conditions, and the MMP-9 remains at a relatively low level. However, in $\mathrm{CHB}$ patients with pathological inflammation, inflammatory factors may promote the expression of MMP-9, thus increasing its level. It was indicated by the results of this study that there were remarkable differences in the MMP-9 expression in CHB patients with varying inflammation grades $(\mathrm{P}<0.05)$, and that the MMP-9 expression level was increased with the aggravated inflammation activity. The reason is that MMP-9 is mainly secreted by inflammatory cells (macrophages and $\mathrm{T}$ cells), and TNF- $\alpha$, IL- 6 and other inflammatory mediators released at the early stage of inflammation can enhance the MMP-9 expression which is consistent with the severity of hepatic inflammation.

An appropriate amount of MMP-9 can degrade ECM deposited temporarily, and it can promote the reconstruction of basement membrane, thus triggering liver fibrosis. However, the liver fibrosis in CHB patients is a pathological repair process of the liver parenchyma against chronic injuries. The results of this study indicated that the differences in the MMP-9 expression in $\mathrm{CHB}$ patients with different fibrosis stages were significant $(\mathrm{P}<0.05)$. It is because only a small amount of MMP-9 is secreted in the body at stage S0. At that moment, the production and degradation of ECM is maintained in a state of homeostasis. With the progression of $\mathrm{CHB}$, however, the state of homeostasis is broken, a large amount of ECM is accumulated in the liver, and liver fibrosis is triggered, thus increasing the fibrosis stage. At this time, massive MMP-9 is secreted in the body to decompose ECM, and pathological repair is conducted by the body itself. MMP-9 level has a positive correlation with fibrosis stage, playing a crucial role in the development of CHB.

In this study, Pearson correlation coefficient analysis showed that the MMP-9 expression level was positively correlated with TNF- $\alpha$ and IL-6 $(\mathrm{P}<0.05)$. This is because TNF- $\alpha$ and IL- 6 can influence the expression of MMP-9 and upregulate the activity of MMP-9 in a concentration- and time-dependent manner, while overexpressed MMP-9 can degrade ECM to destroy the basement membrane and cause disorganized and loose tissue structures, thus leading to further infiltration of TNF- $\alpha$ and IL-6. These factors interact with each other and form a vicious cycle, further resulting in pathological changes of the liver.

In conclusion, MMP-9 can be regarded as a serological marker for judging the severity and progression of $\mathrm{CHB}$, which has very important clinical significance.

\section{Acknowledgements}

Not applicable.

\section{Funding}

No funding was received.

\section{Availability of data and materials}

All data generated or analyzed during this study are included in this published article.

\section{Authors' contributions}

YL, HL and LX wrote the manuscript, performed ELISA, as well as recorded and analyzed the data. All authors have read and approved the final manuscript.

\section{Ethics approval and consent to participate}

This study was approved by the Ethics Committee of Dongying People's Hospital (Dongying, China). Signed informed consents were obtained from the patients or guardians.

\section{Patient consent for publication}

Not applicable.

\section{Competing interests}

The authors declare that they have no competing interests. 


\section{References}

1. Zeisel MB, Lucifora J, Mason WS, Sureau C, Beck J, Levrero M, Kann M, Knolle PA, Benkirane M, Durantel D, et al: Towards an HBV cure: State-of-the-art and unresolved questions - report of the ANRS workshop on HBV cure. Gut 64: 1314-1326, 2015.

2. MacLachlan JH and Cowie BC: Hepatitis B virus epidemiology. Cold Spring Harb Perspect Med 5: a021410, 2015.

3. Roberts H, Kruszon-Moran D, Ly KN, Hughes E, Iqbal K, Jiles RB and Holmberg SD: Prevalence of chronic hepatitis B virus (HBV) infection in U.S. households: National Health and Nutrition Examination Survey (NHANES), 1988-2012. Hepatology 63: 388-397, 2016.

4. Reddy KR, Bourlière M, Sulkowski M, Omata M, Zeuzem S, Feld JJ, Lawitz E, Marcellin P, Welzel TM, Hyland R, et al: Ledipasvir and sofosbuvir in patients with genotype 1 hepatitis $\mathrm{C}$ virus infection and compensated cirrhosis: An integrated safety and efficacy analysis. Hepatology 62: 79-86, 2015.

5. Lamb C and Arbuthnot P: Activating the innate immune response to counter chronic hepatitis B virus infection. Expert Opin Biol Ther 16: 1517-1527, 2016.

6. Jakubowska K, Pryczynicz A, Iwanowicz P, Niewiński A, Maciorkowska E, Hapanowicz J, Jagodzińska D, Kemona A and Guzińska-Ustymowicz K: Expressions of matrix metalloproteinases (MMP-2, MMP-7, and MMP-9) and their inhibitors (TIMP-1, TIMP-2) in inflammatory bowel diseases. Gastroenterol Res Pract 2016: 2456179, 2016.

7. Nguyen K, Pan C, Xia V, Hu J and Hu KQ: Clinical course of chronic hepatitis B (CHB) presented with normal ALT in Asian American patients. J Viral Hepat 22: 809-816, 2015.

8. Bae CB, Kim SS, Ahn SJ, Cho HJ, Kim SR, Park SY, Song GW, Kim DJ, Hwang SG, Yang JM, et al: Caspase-cleaved fragments of cytokeratin-18 as a marker of inflammatory activity in chronic hepatitis B virus infection. J Clin Virol 58: 641-646, 2013.

9. Himaja $\mathrm{N}$ and Shama SN: Herbal wealth for hepatotoxicity: A review. ASIA J Pharm Sci 8: 3-9, 2015.

10. Price J: An update on hepatitis B, D, and E viruses. Top Antivir Med 21: 157-163, 2014.

11. Ofliver KA; Korean Association for the Study of the Liver: KASL Clinical Practice Guidelines: Management of chronic hepatitis B. Clin Mol Hepatol 18: 109-162, 2012.

12. Karev VE: Fas, FasL, and bcl-2 expression on hepatic intralobar lymphocytes in different variants of the natural course of chronic HBV and HCV infection and in its outcomes. Arkh Patol 76: 16-21, 2014 (In Russian).
13. Peng CY, Hsieh TC, Hsieh TY, Tseng KC, Lin CL, Su TH, Tseng TC, Lin HH, Wang CC and Kao JH: HBV-DNA level at 6 months of entecavir treatment predicts $\mathrm{HBeAg}$ loss in $\mathrm{HBeAg}$ positive chronic hepatitis B patients. J Formos Med Assoc 114: 308-313, 2015.

14. Tsamandas AC, Thomopoulos K, Zolota V, Kourelis T, Karatzas T, Ravazoula P, Tepetes K, Petsas T, Karavias D, Karatza C, et al: Potential role of bcl-2 and bax mRNA and protein expression in chronic hepatitis type B and C: A clinicopathologic study. Mod Pathol 16: 1273-1288, 2003.

15. Coffin CS, Osiowy C, Gao S, Nishikawa S, van der Meer F and van Marle G: Hepatitis B virus (HBV) variants fluctuate in paired plasma and peripheral blood mononuclear cells among patient cohorts during different chronic hepatitis B (CHB) disease phases. J Viral Hepat 22: 416-426, 2015.

16. Aoudjit F, Estève PO, Desrosiers M, Potworowski EF and St-Pierre Y: Gelatinase B (MMP-9) production and expression by stromal cells in the normal and adult thymus and experimental thymic lymphoma. Int J Cancer 71: 71-78, 1997.

17. Chen J, Xu W, Chen Y, Xie X, Zhang Y, Ma C, Yang Q, Han Y, Zhu C, Xiong Y, et al: MMP-9 facilitates hepatitis B virus replication through binding with IFNAR1 to repress IFN/JAK/STAT signaling. J Virol 91: e01824-16, 2017.

18. Zhao ZH, Fan YC, Zhao Q, Dou CY, Ji XF, Zhao J, Gao S, Li XY and Wang K: Promoter methylation status and expression of PPAR- $\gamma$ gene are associated with prognosis of acute-on-chronic hepatitis B liver failure. Clin Epigenetics 7: 115, 2015.

19. De Simone V, Franzè E, Ronchetti G, Colantoni A, Fantini MC, Di Fusco D, Sica GS, Sileri P, MacDonald TT, Pallone F, et al: Th17-type cytokines, IL- 6 and TNF- $\alpha$ synergistically activate STAT3 and NF- $\mathrm{KB}$ to promote colorectal cancer cell growth. Oncogene 34: 3493-3503, 2015.

20. Somal A, Aggarwal A and Upadhyay RC: Effect of thermal stress on expression profile of apoptosis related genes in peripheral blood mononuclear cells of transition Sahiwal cow. Iran J Vet Res 16: 137-143, 2015.

(†) $\odot$ This work is licensed under a Creative Commons Attribution-NonCommercial-NoDerivatives 4.0 International (CC BY-NC-ND 4.0) License. 